\title{
O desenho urbano e o envelhecimento populacional: reflexões sobre o Plano Piloto de Brasília
}

\author{
Autor: Maria Eduarda Vasconcelos de Almeida \\ Orientador: Dr. Sávio Tadeu Guimarães \\ Coorientadora: Dra. Maria Eleusa Montenegro \\ Linha de pesquisa: Teoria, história e projeto de habitação.
}

\section{INTRODUÇÃO}

A questão do envelhecimento populacional de forma autônoma e sustentável e suas relações com o espaço urbano envolvem múltiplas perspectivas.

Para se esclarecer questões de envelhecimento ligadas à renovação urbana, devemos primeiramente especificar os conceitos presentes nas duas premissas. "velhice e envelhecimento"; são dois conceitos que não são claramente definidos sociologicamente ou cientificamente.

A velhice é frequentemente tratada como uma fase da vida, um estado estático, enquanto envelhecimento é um processo, um fenômeno dinâmico e contínuo. A extensão da expectativa da vida é constantemente alimentada por novas pesquisas médicas, progressões socioeconômicas, melhora das condições sanitárias, acesso à tecnologia da informação. Portanto, o número de idosos aumenta progressivamente.

Tratando-se do Plano Piloto de Brasília, faz-se necessário compreender, preliminarmente, a relação entre as práticas de estruturação, transformação e apropriação do território e as dimensões sociais, psicológicas e comportamentais, sempre sob a ótica da terceira idade.

A partir dessa perspectiva, analisa-se a relação da população idosa em crescimento nas superquadras tradicionais de Brasília e o espaço urbano existente, traçando-se um panorama do peso do papel do desenho urbano na inclusão do idoso na vida comunitária, reconhecendo suas preferências e necessidades e respeitandose o estilo de vida adotado por aquela comunidade.

Obviamente muita coisa mudou, sociologicamente falando. A violência, as relações entre os habitantes, o sentimento comum em relação ao futuro do País, o desequilíbrio social. A cidade, que deveria ser um espaço democrático, hoje tem outro 
perfil, e nela não se encontram a equidade de tratamento, de oferta de moradia, de diferentes classes que coabitam e se respeitam, de oferta de trabalho, de condições de deslocamento.

Vários estudos já foram e vêm sendo feitos, por diferentes pesquisadores em diferentes áreas do conhecimento, sobre os problemas da exclusão, da violência, da degradação ambiental, da segregação socioespacial, da baixa apropriação do espaço público em Brasília. Não se vê com muita frequência, no cotidiano do Plano Piloto, exceto raras ressalvas, um senso de comunidade, um núcleo de convívio, de trocas, de atividades, de eventos culturais, de recreação, de observação da vida cotidiana. $O$ que se pensa é sobre o espaço urbano da superquadra, que deveria ser utilizado no dia a dia da população, como prática cotidiana. As superquadras seriam hoje fruto de um ordenamento urbano que resultou em "uma transformação da cidade numa porção de territórios hostis e desconfiados uns dos outros"? (JACOBS, 2011, p. 127)

O objetivo principal deste trabalho foi a obtenção de dados e posterior avaliação do impacto do desenho urbano, do planejamento urbano e/ou da gestão urbana sobre a qualidade de vida dos habitantes de terceira idade da Asa Sul. Assim, procura-se delinear possíveis conexões entre o momento histórico e social no qual a cidade foi planejada e as condições atuais do espaço urbano, para então lançar questionamentos e proposições acerca dos impasses e desafios para o planejamento futuro e da presente adaptação da cidade às demandas da população idosa, de acordo com legislação específica.

Segundo Henri Lefèbvre (2006, p. 139), o direito à cidade é um direito "[...] à vida urbana, à centralidade renovada, aos locais de encontro e de trocas, aos ritmos de vida e empregos do tempo que permitem o uso pleno e inteiro desses momentos e locais". Devemos, portanto, considerar que o direito à cidade é um direito comum, antes de ser individual, e depende da ação do coletivo para atuar e transformar os espaços, coordenando e planejando o processo de urbanização.

Tendo como base tais pressupostos, tanto o interesse em um tema cada vez mais discutido no planejamento das cidades quanto a observação relativa a premissas e fatores que influenciam a vivência e o entendimento das cidades, este projeto de pesquisa se justifica pelo propósito de avaliar sob essa ótica um espaço muito peculiar e diferenciado: a superquadra.

Além disso, a pesquisa contribui para iniciativas afins à linha de investigação configuracional, ao incluir uma série de dissertações e teses já defendidas e 
bibliografias abrangentes, que abordam temas diversos como geriatria, sociologia, planejamento urbano, psicologia e antropologia.

Portanto, a ideia está na conjugação de esforços para melhor compreender a cidade de Brasília, especificamente o Plano Piloto, Asa Sul, com o olhar em envelhecimento populacional.

Como conclusão, propõe-se a reflexão sobre alguns aspectos dos arranjos urbanos do projeto do Plano Piloto, assim como um debate sobre elementos que tornam a cidade mais amigável ao idoso, incluindo itens que impactam na autonomia e independência, saúde e bem-estar, conectividade social e segurança.

\section{METODOLOGIA}

Ao determinar-se que seria essencial entender os conceitos fundamentais para a compreensão do tema estudado, foi estabelecido um marco teórico-metodológico, que envolve o levantamento de textos históricos e revisões de literatura, de maneira a posteriormente, mediar estas informações com uma pesquisa empírica.

Em primeiro lugar, a intenção foi descrever o marco histórico no qual o planejamento da cidade se desenvolveu; quais eram os conceitos aplicados naquele determinado momento, e os elementos e utopias que ilustravam a tentativa de estabelecer parâmetros que fariam parte do cotidiano da vida na cidade e suas relações sociais e econômicas. Para isso, será consultada bibliografia especifica que descreve as intenções do projeto do Plano Piloto, além de textos que auxiliem na análise crítica dos elementos adotados nos projetos urbanos desenvolvidos após a segunda guerra mundial, baseados em paradigmas modernistas estabelecidos pelo Congresso Internacional de Arquitetura Moderna (CIAM) em 1920 (CIAM,1933).

Após esse entendimento, será feita uma comparação entre a intenção e variáveis pensadas por Lucio Costa para o cotidiano e a comunidade no Plano Piloto e alguns parâmetros que hoje se aplicam nos conceitos contemporâneos de planejamento urbano, baseados em literatura relevante.

O processo de análise do espaço da superquadra e suas relações com os idosos se mostrou bem mais complexo do que o avaliado incialmente. Em uma primeira análise, julgamos que seria possível definir uma área de estudo a partir de dados coletados em agências públicas de pesquisas demográficas, como a Companhia de Planejamento do Distrito Federal (Codeplan). 
Entretanto, após analisar algumas pesquisas e levantamentos, mais especificamente ao estudar o PDAD - Pesquisa Distrital de Amostras de Domicílios, percebi que o perfil de ocupação das superquadras pelos idosos ainda é incerto, complexo e pulverizado, o que significa que seria impossível identificar uma determinada quadra com maior concentração de pessoas com mais de 60 anos.

Para confirmar esse dado, consultei a Professora Ana Maria Nogales Vasconcelos, doutora em Demografia pela Université Catholique de Louvain, na França, e professora do Departamento de Estatística da Universidade de Brasília, coordenadora do Laboratório de População e Desenvolvimento em Projetos na área da saúde e vulnerabilidade social, vinculado ao Núcleo de Estudos Urbanos e Regionais (NEUR/CEAM) da Universidade de Brasília. Sendo grande conhecedora da realidade do Distrito Federal, Ana Maria foi de grande ajuda na reflexão sobre a área de abrangência da pesquisa. Segundo sua orientação, nenhuma das quadras da Asa Sul poderia ser considerada um modelo para aplicabilidade dos questionamentos e resultados obtidos em relação aos idosos no Plano Piloto, pois se trata de uma população ainda dispersa em relação à concentração ou não em determinada área urbana.

A abordagem qualitativa foi a opção metodológica escolhida para viabilizar a investigação em relação às relações do indivíduo com o espaço urbano, permitindo o reconhecimento de necessidades individuais e possibilitando a coleta de impressões pessoais. O que se entende é que os sujeitos participantes de uma pesquisa são, afinal, os portadores do conhecimento da memória da cidade e devem ser compreendidos como atores sociais, respeitando-se suas opiniões, posicionamentos e particularidades. Segundo Minayo (2008), “[...] a fala dos sujeitos de pesquisa é reveladora de condições estruturais, de sistemas e valores, normas e símbolos [...]", e por isso mesmo essa fala é tão rica e reveladora.

A realização da pesquisa com os moradores de 60 anos ou mais das superquadras foi aprovada pelo Comitê de Ética em Pesquisas (CEP) do Centro Universitário de Brasília - UniCEUB, sob parecer n 3.175.533, em 27 de fevereiro de 2019, e submetida à Comissão Nacional de Ética em Pesquisa (Conep), do Conselho Nacional de Saúde (CNS), Plataforma Brasil do Governo Federal, Ministério da Saúde, sob a condição de pesquisa que envolve seres humanos, cumprindo normas e diretrizes reguladoras conforme a Lei. 
Os questionamentos partiram das proposições definidas pelo Guia global: a cidade amiga do idoso, da Organização Mundial da Saúde (OMS, 2008) e destacam os ambientes e elementos a serem investigados: edificações e espaços abertos, transporte e moradia (ambientes físicos); participação e bem-estar mental (ambientes sociais e culturais); a comunicação e informação, apoio comunitário e serviços de saúde (ambientes de convivência e de saúde).

Para refinar e objetivar o estudo, adotou-se a metodologia de Dorneles, Ely e Pedroso (2006), que identificam critérios sobre a boa inserção de pessoas de terceira idade no espaço público urbano. Destaque-se aqui que os critérios funcionam como checklist, um instrumento de verificação das características amigáveis aos idosos.

A abordagem qualitativa foi, portanto, a opção metodológica escolhida para viabilizar a investigação em relação às relações do indivíduo com o espaço urbano, permitindo o reconhecimento de necessidades individuais e possibilitando a coleta de impressões pessoais.

As necessidades dos idosos no espaço urbano públicos foram classificadas em:

Necessidades físicas: Relacionadas à saúde física, segurança e conforto dos indivíduos no espaço urbano, apresentando-se livre de obstáculos e de fácil manutenção a fim de evitar acidentes.

Necessidades informativas: Relacionadas ao modo como a informação sobre o meio no qual estão inseridos é processada. A percepção (processo de obter ou receber a informação do ambiente) e a cognição (representa o modo como a pessoa organiza a informação recebida) são identificados como aspectos importantes para o processamento da informação. Deve-se considerar neste item as dificuldades visuais, por exemplo.

Necessidades sociais: Referem-se à promoção do controle da privacidade ou interação social, dizendo respeito ao significado atribuído pelo idoso ao espaço público pelo qual circula. As mudanças características da vida urbana, representando também, um fator significativo de identidade das cidades, o que contribui para a sua estruturação.

Além desses aspectos, foram avaliados itens relativos a conforto acústico e térmico, paisagem e escala urbana, continuidade e ocupação do espaço público, ergonomia e segurança. 
Todo material foi registrado através da catalogação dos resultados obtidos através do questionário e por levantamento fotográfico, e foi organizado de maneira a reunir o conteúdo em categorias analíticas ou tópicos, de maneira a facilitar a análise dos resultados e evitar registros simbólicos ou polissêmicos.

\section{ANÁLISE DE DISCUSSÃO DE DADOS}

Ao mesmo tempo em que devemos tratar os aspectos físicos e plausíveis da questão, devemos entender como o espaço urbano pode se modificar por um planejamento proativo, voltado a uma população idosa que, ao ser beneficiada, beneficia também a toda uma comunidade que se vê amparada por uma política urbana justa e democrática.

Modificando o ambiente urbano, com adaptações dos espaços físicos fundamentais para desenvolvimento das atividades, é uma estratégica para melhorar de maneira geral a acessibilidade e a infraestrutura urbana.

Atualmente, a expectativa de vida do brasileiro alcançou a maior média da história: 76 anos. Até 2060, a população com mais de 60 anos mais que dobrará e atingirá $32,1 \%$ do total de habitantes. Isso representa $13,44 \%$ do total de habitantes do País. Em 2060, um quarto (25\%) da população terá mais de 65 anos - e a expectativa de vida será de 81 anos. O contrário ocorre na população de crianças de até 14 anos, que atualmente representa $21,3 \%$ do total e que em 2060 representará $14,7 \%$. Paralelamente a isso, temos o fato de que $84 \%$ da população brasileira vive em áreas urbanas (BRASIL.IBGE, 2018).

Portanto, a hipótese a ser testada é exatamente como o planejamento urbano e algumas pequenas ações pontuais na área pública poderiam propiciar uma melhor qualidade de vida em comunidade para a população idosa.

O espaço público da superquadra, entendido como espaço de uso comum e de posse coletiva, tem que atrair essa população, garantindo a boa acessibilidade, o respeito, a segurança e a boa convivência social. Espaços de circulação (ruas e praças), espaços de lazer e recreação, espaços de contemplação e espaços de preservação são espaços a ser compartilhados, com a compreensão de que são espaços públicos, de direito de todos. 
Brasília não foi o primeiro nem o mais abrangente exemplo de aplicação das regras do modernismo no planejamento urbano, mas é a única cidade moderna a ser considerada patrimônio histórico da humanidade, o que comprova sua importância.

A revista Acrópole publicou, em fevereiro de 1960, uma edição totalmente dedicada à nova capital, com textos em português e inglês, de autoria de Eduardo Kneese de Mello, Lucio Costa, Oscar Niemeyer e do próprio Presidente Juscelino Kubitschek, entre outros. Jorge Wilheim assim descreve o futuro de Brasília:

Neste centro, haverá vielas em que se distribuirão as casas de espetáculos, espaços íntimos que lembrarão a Rua do Ouvidor ou o antigo Largo da Misericórdia de São Paulo. As lojas e restaurantes anexos à estação rodoviária serão certamente importantes pontos de encontro. (ACRÓPOLE, 1960)

O Governo Federal e o Governo do Distrito Federal são, em conjunto, responsáveis pela complementação, preservação, adensamento e expansão urbana da cidade, para assim manter as características essenciais do conjunto urbanístico, arquitetônico e paisagístico da Capital.

Além da proteção Distrital e Federal, Brasília conta com a chancela de proteção da Unesco desde 7 de dezembro de 1987, data em que a cidade foi reconhecida como Patrimônio Cultural da Humanidade, com base no conceito de que se trata da única capital do mundo totalmente projetada e construída de acordo com os ideais modernistas, por meio do Decreto 10.829/1987 (DF, 1987).

As escalas - monumental, residencial, gregária e bucólica- são o princípio fundamental da preservação do conjunto urbanístico, arquitetônico e paisagístico de Brasília. A identidade e originalidade do conjunto urbanístico se mantém nas escalas monumental, residencial, gregária e bucólica, representando o monumento a ser preservado para a posteridade. Vale lembrar que esse tombamento ocorreu com a cidade ainda em formação, o que por vezes provoca teses enganosas acerca da sua renovação construtiva e do contínuo desenvolvimento pelo qual todas as cidades naturalmente passam. A cidade viva e aprazível de Lucio Costa passa, primeiramente, pelas escalas, construídas e solidificadas pelos candangos, e depois pelos seus habitantes.

A partir do detalhamento e complementação do Plano Piloto de Lucio Costa, descrito no Decreto no 10.829/87 - Brasília Revisitada, definindo novas áreas residenciais no Plano Piloto e nos principais eixos viários e do reconhecimento de Brasília como Patrimônio Cultural da Humanidade pela Unesco, em 1987, procurou- 
se assegurar o cumprimento dos princípios arquitetônicos e urbanísticos no Plano Piloto, sob forte pressão de demanda por unidades habitacionais (COSTA, 1985).

No caso do Plano Piloto, ao se analisar atualmente o espaço físico da superquadra tradicional, na Asa Sul, percebem-se de imediato alguns fatores que levam a um questionamento mais amplo: a desigualdade social, em relação ao tipo homogêneo de habitante que hoje ocupa os edifícios, em termos de renda, cor e etnia; e o esvaziamento do espaço público, a deficiência de serviços e equipamentos, a precariedade de manutenção do mobiliário urbano e das calçadas.

No entanto, ao analisar o memorial descritivo de Lucio Costa, fica claro que as superquadras são concebidas para reestruturar as relações coletivas de moradia. Ou seja, o arquiteto seria o personagem central no planejamento não só das cidades, mas também nos aspectos da vida social e econômica inseridos no ambiente urbano.

Pode-se dizer, então, que atualmente o pequeno núcleo urbano da superquadra reflete as desigualdades geradas em outras esferas e comuns, infelizmente, na sociedade brasileira, como, por exemplo, a irregularidade na distribuição de renda. Pensando no direito à cidade e ao lugar, a cidade capitalista global, sustentada pelos valores do livre mercado, transformou-se em um bem de consumo, e seus habitantes vivem dependendo de sua capacidade de consumir o que aquela aglomeração urbana lhes oferece (HARVEY, 2018).

De acordo com a organização não governamental PPS - Project for Public Spaces (PPS, 2019) que se dedica a criar e manter lugares públicos de qualidade em conjunto com as comunidades locais, os espaços urbanos, para serem bem vistos pela população, devem ter geralmente quatro características: acessibilidade facilidade de acessar e transpor o espaço, além da conectividade, capilaridade e mobilidade; usos e atividades - as pessoas têm que estar comprometidas em desenvolver atividades no local; estética - o espaço é confortável e tem boa aparência; e sociabilidade - um espaço convidativo, que possibilite encontros e no qual as pessoas queiram permanecer, conversar com amigos e interagir com desconhecidos.

Para pensar em uma cidade amigável aos idosos, é preciso pensar em duas estratégias de design urbano: uma seria o planejamento urbano que favorece a todos, e outra, ações específicas para atender às necessidades dos idosos. Hoje, com uma abordagem contemporânea da vida em sociedade e a vivência do espaço urbano e suas particularidades, as quais podemos testemunhar diretamente, problemas como 
a violência urbana, a mobilidade, a gentrificação e o desrespeito à memória dos mais velhos em relação ao espaço que habitam devem fazer parte dos questionamentos em relação à vida em sociedade e ao futuro das nossas cidades. Para que as atividades sejam prazerosas para os mais velhos, as necessidades são comuns a qualquer comunidade no mundo: autonomia e independência, saúde e bem-estar, conectividade social e segurança.

No Plano Piloto o desenho urbano é fruto de um processo consciente, pois a forma urbana é um objeto derivado de um processo de concepção anterior à sua concretização como espaço. A intenção específica dos planejadores urbanos orienta a configuração da forma urbana idealizada, eternizada pelos condicionantes indicados posteriormente, no processo de tombamento de Brasília como Patrimônio Cultural da Humanidade.

Já o planejamento urbano tem como objeto e objetivo o desenvolvimento urbano. Sendo entendido como um processo, e não um produto, o planejamento é sempre uma atividade de ordenamento de atos e de elementos para o cumprimento de metas e o alcance de um objetivo predeterminado. O que se leva em conta são os elementos que contribuem com o futuro, a antevisão de fenômenos e a previsão de comportamentos

O fato de haver um plano urbanístico a priori, uma destinação de espaços segundo uma setorização bem clara, uma definição de usos e ocupações do território antes mesmo de a cidade ser implantada e um centro delimitado com uma função preestabelecida não impediu a seletividade espacial e a valorização dos espaços do Plano Piloto, características presentes de um modo geral no processo de metropolização no Brasil.

E, para incentivar o uso do espaço público, é preciso pensar nos cidadãos que moram, circulam, estudam, trabalham, consomem, usam e prestam serviços, expõem opiniões coletivamente como sociedade democrática e se divertem em espaços que devem se apresentar adequados ao lazer, com jardins, quadras de esporte, espaços destinados à contemplação, às trocas, à preservação, à conservação... Ou seja, concretizar o que nos vem em mente quando Lucio Costa descreve, em seu relatório do Plano Piloto de Brasília (COSTA, 1957), um espaço vibrante e pulsante, onde uma dinâmica urbana favorece a vitalidade das áreas da cidade, regeneradas por pequenas ações e intervenções pontuais listadas nos parâmetros de desenho urbano contemporâneo, respeitando os valores históricos de uma cidade modernista 
A sugestão é de se testar algumas categorias de intervenções projetuais, como melhores fluxos e acessos, itens relativos a implantação e localização e a segurança pública, e itens relativos ao que for inferido em pesquisa no sentido do entendimento da informação e da percepção do espaço urbano, mobiliário urbano, pisos e jardins, para que seja construído um espaço de convivência na superquadra acessível e confortável para os idosos, melhorando sua segurança e autonomia e permitindo sua inclusão social de forma mais efetiva.

Algumas ações sugeridas pela Organização Mundial da Saúde, através da Rede Global para Cidades e Comunidades Amigas dos Idosos, são de simples implantação e de grande impacto, como ampliação do tempo de duração dos semáforos. Basicamente, podemos pensar em adaptar as superquadras em termos de adequação dos espaços livres, melhoria da mobilidade, sociabilidade e segurança, pensando na comunidade crescente de pessoas com 60 anos ou mais.

Outras ações deveriam ser implantadas em uma escala maior, na cidade como um todo, como travessias de pedestres seguras, faixas antiderrapantes e sinais de áudio quando necessário, itens gerais de acessibilidade e a eliminação de diversas barreiras físicas, rampas adaptadas para espaços públicos e a previsão de ambientes seguros - "A sensação de segurança no ambiente de vida compartilhada afeta fortemente a predisposição das pessoas para se deslocarem na cidade e interagirem com a comunidade local", segundo a OMS (OMS 2008).

\section{CONCLUSÕES}

A definição e análise de valores e critérios para identificação de elementos urbanos que interferem na qualidade de vida do idoso nas superquadras de Brasília é crucial nesse momento aonde o envelhecimento da população predominante no Plano Piloto é mais evidente, e mais facilmente passível de avaliação. Com o amadurecimento da cidade e a passagem do tempo, a vivência do espaço urbano e as claras modificações que a cidade foi sofrendo aliadas à própria mudança do perfil do habitante típico do Plano Piloto, permitem que esta análise possa ser feita com mais clareza e objetividade.

Em 2010, existiam 39 idosos para cada grupo de 100 jovens; em 2040, estimase o número de 153 idosos para cada 100 jovens. Como o conceito e aplicação do planejamento urbano modernista é relativamente recente, as consequências da 
qualidade do espaço urbano na vida de uma população que inexistia há alguns anos atrás na Capital do País ainda fazem parte de um campo a ser estudado.

Claramente, o País não está preparado para lidar com as necessidades do envelhecimento populacional, tanto do ponto de vista social quanto do ponto de vista de gestão e planejamento urbano.

Segundo Peixoto (2003), os espaços urbanos públicos e a céu aberto têm papel fundamental na sociabilidade dos idosos. São as praças, por exemplo, que thes permitem o estabelecimento das relações sociais com os mais jovens, e também se configuram como um espaço próprio, um "canto" favorito dentro da urbe. A mudança do papel desempenhado no núcleo familiar não produz uma ruptura dos laços familiares, mas o convívio não é mais praticado predominantemente na esfera familiar. Sendo assim, a importância dos espaços públicos é imperativa na velhice saudável e inclusiva.

A superquadra é a escala do usuário objeto deste estudo, que leva em conta fatores como habitabilidade, mobilidade e promoção da participação dos cidadãos. Para se trabalhar em elementos urbanos que impactam na qualidade de vida do dia a dia dos idosos, a intenção é que os espaços públicos venham a ser voltados para pessoas, com ênfase na interação, saúde e recreação em uma escala "micro". O uso da cidade vai além do deslocamento feito por modais passivos. Os pedestres com mobilidade reduzida teriam prioridade real.

O conceito de cidades vivas, seguras, confortáveis, sustentáveis, saudáveis passa pela escala humana - em termos de dimensões. Os locais devem ser acolhedores, e não dispersores; promover encontros, e não dispersar a população; ter distâncias apropriadas para se caminhar e pedalar.

Em resumo, reverter um quadro que combina uma herança dos princípios de configuração do movimento moderno, o protagonismo de um Estado burocrático e autoritário, uma legislação urbanística ineficiente com uma sociedade de classe média cujos valores ignoram, ampliam e favorecem a segregação socioespacial é tarefa complexa. Os instrumentos iniciais para rompimento desse quadro passam pela participação social, pelo reconhecimento da diversidade social e urbanística, pela valorização do espaço público e pelo debate democrático.

O respeito ao desenho modernista formalizado no plano de Lucio Costa, neste sentido, parece imobilizar iniciativas que podem ser consideradas simples do ponto de vista do planejamento urbano - como, por exemplo, a inclusão de mobiliário urbano 
e possibilitar o uso mais diversificado de equipamentos públicos, como escolas e praças.

Como qualquer cidade do mundo, a estrutura deve ser acolhedora, para que se evite $\mathrm{o}$ isolamento amedrontado, a inatividade e a exclusão social. Uma cidade "tradicional" (no sentido mais amplo do conceito) oferece, por si só, espaços de encontro mais convencionais - praças, esquinas, quarteirões, diversidade, vizinhanças ortogonais.

No caso da superquadra, dois fatores importantes já estão presentes para promover a velhice ativa: grandes áreas verdes e grandes espaços públicos que podem ser compartilhados. O que poderia ser feito para melhorar uma cidade como Brasília, tendo em vista a terceira idade?

O mesmo que pode ser feito em qualquer cidade do mundo: incentivar a permanência dos idosos no meio urbano no qual tem familiaridade, promover pequenas ações que facilitariam a melhoria das relações destes indivíduos com o espaço urbano: instalação de sinais táteis, pisos diferenciados e apropriados nas escadas e rampas; retirada de obstáculos do percurso dos pedestres, sejam eles quais forem; instalação de bancos e mobiliário urbano adaptados inclusive a quem tem algum tipo de deficiência motora; manutenção de calçadas, cuidados com os jardins, especialmente no cinturão verde que circunda a superquadra, manutenção de faixas de travessia de pedestres, redução da velocidade na parte interna da superquadra.

Levando-se em conta a opinião direta dos interessados quanto ao espaço físico existente, no caso os moradores, especificamente a população acima de 65 anos, verificou-se que há ampla insatisfação com os elementos do espaço urbano de circulação, em termos de conforto, seguridade, continuidade e segurança, em particular no que diz respeito a desníveis e obstáculos observados nas calçadas, assim como com a iluminação deficiente. Os idosos, com suas características e dentre tantos sujeitos urbanos, percebem as limitações de acessibilidade e de mobilidade urbana no espaço por onde circulam para exercer suas atividades cotidianas.

Assim, considerando o envelhecimento populacional no Plano Piloto de Brasília, mais especificamente na Asa Sul, verifica-se o aumento de barreiras arquitetônicas e urbanísticas que comprometem o deslocamento do idoso no espaço urbano de circulação e colocam em risco a sua integridade física. Premissa obrigatória 
é a eliminação de tais barreiras, a fim de possibilitar a construção de uma sociedade inclusiva, que permita ao idoso se deslocar com autonomia e segurança.

Outra questão importante se relaciona a respeito e inclusão social. Aparecem também como necessidades imperativas: participação cívica, possibilidades de comunicação e informação, apoio comunitário e serviços de saúde, atividades culturais e locais de lazer. A cultura do envelhecimento é a cultura da solidariedade, que deve ocorrer entre ricos e pobres, entre público e privado, entre regiões, entre culturas. E, acima de tudo, a solidariedade deve ocorrer entre jovens e idosos.

Ainda que o próprio conceito da velhice seja flexível, pois é marcado por várias definições sobre as diversas formas de envelhecimento, que dependem de gênero, classe social, educação, identidade cultural, parâmetros sociais e outros, o que deve existir é a valorização de espaços urbanos, coletivos e sociais, em detrimento dos espaços domésticos, a fim de possibilitar uma velhice rejuvenescida, que se beneficiaria de projetos e serviços de lazer, novos grupos sociais, programas culturais e várias outras formas de interação social.

A interação e a contribuição positiva de arquitetos e planejadores urbanos, obviamente sempre em conjunto com a população, governantes, líderes comunitários, interventores, agentes da cultura popular e os diversos atores que ocupam o espaço urbano é a chave para a mudança. A maneira como a cidade de Brasília, mais especificamente o Plano Piloto, é administrado, a infraestrutura existente, os serviços que estão disponíveis e os espaços construídos são os principais fatores para reflexão, na medida em que podemos pensar em possíveis contribuições para um sistema mais inclusivo e resiliente, com nossas comunidades integradas ao processo de envelhecimento.

Assim como a cidade contemporânea, o desenho urbano atual não pode ser linear e se apoiar em uma ou outra teoria. A complexidade das cidades faz com que o exercício do projeto seja baseado no reconhecimento das frequentes mutações ocorridas na sociedade; na esfera urbana contemporânea, o projeto não é mais um rígido ordenamento do território, um desenho final, e sim um veículo para viabilizar transformações. 


\section{REFERÊNCIAS}

ACRÓPOLE. São Paulo: Brasília. Edição 256 fevereiro 1960. Disponível em: <http://www.acropole.fau.usp.br>. Acesso em: 01 jan. 2020.

BRASIL.IBGE. Projeção da população. 2018. Disponível em:

$<$ https://www.ibge.gov.br/estatisticas/sociais/populacao/9109-projecao-dapopulacao.html?=\&t=resultados $>$. Acesso em: 14 jan. 2020.

CIAM CARTA de Atenas. Assembleia do CIAM, 1933. Disponível em:<http://portal.iphan.gov.br/portal>. Acesso em: 02 jan. 2018.

COSTA, Lucio. Relatório do Plano Piloto de Brasília. Distrito Federal: NOVACAP, 1957.

. Brasília Revisitada. Brasília. 1985/1987.

DISTRITO FEDERAL. Decreto n. 10.829, de 14 de outubro de 1987. Baseado no documento Brasília Revisitada, elaborado por Lucio Costa em 1985-1987.

Complementado pela Portaria n. 314, de 8 de outubro de 1992, do Instituto Brasileiro de Patrimônio Cultural. Regulamenta o art. 38 da Lei n. 3.751, de 13 de abril de 1960, no que se refere à preservação da concepção urbanística de Brasília.

Disponível em:

<http://www.sinj.df.gov.br/sinj/Norma/15139/exec_dec_10829_1987_rep.html>. Acesso em: 13 jan. 2020.

DORNELES, V. G.; ELY, V. H.; PEDROSO, E. S. R. A inserção do idoso no espaço público urbano. 2006. Disponível em:

<http://www.infohab.org.br/entac2014/2006/artigos/ENTAC2006_2732_2741.pdf>. Acesso em: 22 ago.2018.

HARVEY, David. A Liberdade da Cidade. GEOUSP, Espaço e Tempo (Online), abr. 2018. Disponível em: <https://doi.org/10.11606/issn.21790892.geousp.2009.74124>. Acesso em: 03 abr. 2019.

JACOBS, Jane. Morte e vida de grandes cidades. São Paulo: Martins Fontes, $1961 / 2011$.

LEFÈBVRE, Henri. O direito à cidade. São Paulo: Centauro, 2006.

MINAYO, Maria Cecília de Souza. O desafio do conhecimento. 11. ed. São Paulo: Hucitec, 2008.

OMS. Organização Mundial de Saúde. Guia global: Cidade Amiga do Idoso. Publicações OMS, 2008.

PEIXOTO C. Entre o estigma e a compaixão e os termos classificatórios, Velhice ou Terceira Idade? Estudos Antropológicos sobre identidade, memória e política (3. ed.). Rio de Janeiro: FGV, 2003. 
PPS. Project for Public Spaces. What makes a successful place? Disponível em: <https://www.pps.org/article/grplacefeat>. Acesso em: 10 jul. 2019.

UNITED NATIONS - Departamento de Assuntos Econômicos e Sociais, DESA/ Population Division. World Population Prospect: The 2019 Revision. Publicações OMS, NewYork, 2019. Disponível em:

<https://population.un.org/wpp/Publications/Files/WPP2019_DataBooklet.pdf>. Acesso em: 14 jan.2019. 